\title{
MANAGERS OF TOURISM COMPANIES CAN NO LONGER EXPECT ANY FINANCIAL SUPPORT FROM COMPANY OWNERS: DIFFERENT WORKING CAPITAL MANAGEMENT DUE TO THE GLOBAL FINANCIAL CRISIS
}

\section{Tomáš Heryán ${ }^{1}$}

\begin{abstract}
Silesian University in Opava, School of Business Administration in Karviná, Department of Finance and Accounting, Czech Republic, ORCID: 0000-0003-2027-7149, heryan@opf.slu.cz.
\end{abstract}

Abstract: Tourism evidence is more and more often among the research literature because of its importance for the economy. Nonetheless, there is still a huge gap in recent literature related to its financial issues, the microeconomics of tourism in other words. This particular paper focuses neither on economic growth, nor the number of arrivals, which is both the most common fields in literature. It focuses on the financial management of middle-sized hotels and travel agencies. The aim of the study is to estimate the relationship between profitability and both, working capital management and reinvestments of companies' owners of medium-sized hotels and travel agencies in the period affected by the global financial crisis. Annual data from two international databases, Amadeus and Orbis, are used to compare differences caused by the global financial crisis and later on, the Euro crisis. Both of these economic events affected even tourism without any doubts. According to a character of variables the General Method of Moments (GMM) with panel data is deployed as the main estimation method. There is an effort made to explain this particular regression method and all reasons for its usage, more importantly, to explain that a reader in a clear way. The results of this study have proven that managers cannot expect any financial support from owners of tourism companies. Even though the owners were obviously distributing the earnings during the crisis period, managers were able to increase the net working capital apparently. Therefore, on the contrary, owners would put the pressure on managers to employ a riskier payment policy of middlesized hotels and travel agencies after the crisis.

Keywords: Tourism, hotels and travel agencies, financial health, GMM estimation.

JEL Classification: C50, D20, Z33.

APA Style Citation: Heryán, T. (2020). Managers of Tourism Companies Can no Longer Expect any Financial Support from Company Owners: Different Working Capital Management Due to the Global Financial Crisis. E\&M Economics and Management, 23(1), 50-59. https://doi.org/10.15240/tul/001/2020-1-004

\section{Introduction}

In several economies, tourism is the key field representing an engine of economic growth. This field is employing directly or indirectly a big part of the economically active population. Above that, tourism belongs to the services, which bring an added value itself. A recent global financial crisis, which negatively reflected a real economy development ten years ago, unfortunately, influenced tourism, too. Even if the role of a central bank is very distant from tourism, a consequent unconventional 
monetary policy within the sovereign debt crisis in the Eurozone undoubtedly influenced it as well (Heryán, 2017). Rather than macroeconomy and turbulent development in financial markets, which can relate to tourism in very different ways, it is more contributive to deal with a microeconomic aspect of company internal processes of hotels and travel agencies (Heryán, 2018).

The representative conflict between shareholders and managers has been one of the most frequent topics in the scientific literature since the mid-20th century. Profits being reinvested back into the business or paying a share of profits to business owners. This single sentence can characterize a conflict where both sides of the coin, the managers and the owners are eager for available financial resources. In terms of profitability and growth of company market value, profit management is generally a key issue for any company (Miller \& Modigliani, 1961). Working capital ratios are a useful tool when assessing the financial strength and immediate solvency of a company. From an operational point of view, the main interest of the financial manager is current and near-future cash flows. In case he has no means for immediate repayment, then he is definitely supported by the existence of sufficient working capital (Sagan, 1955).

This paper aims to estimate the relationship between profitability and both, working capital management and reinvestments of companies' owners of medium-sized hotels and travel agencies in the period affected by the financial crisis. Emphasizing the conflict of interests between managers and owners of the selected medium-sized companies in the tourism field in the Czech Republic is the main contribution of this paper. Obviously, hotels and travel agencies have suffered considerable losses as a result of the global financial crisis, within which, from a financial perspective, the business itself became risky. On the other hand, more profits from previous years were distributed. As it comes to tourism, a methodology should be very cautious. Economic data of the tourism industry are often incomplete and have many shortcomings. Due to the short time series or due to missing data, it is absolutely impossible to make such data as the subject of basic causality analyzes such as linear regression model or cointegration analysis. The endogeneity of selected variables in the form of financial analysis indicators, and last but not least, the characteristics of the model random component are other important problems. It is clear though that data have to be examined using more sophisticated methods. However, such econometric methods are often inaccessible to the ordinary user because of their complexity and difficulty to understand the higher statistics, or applied or even theoretical mathematics. The contribution of this work is also the approximation of modeling of data arranged in panels to the common reader.

\section{Literature Review}

The tourism economy collects a wide range of very diverse studies pointing out the importance of tourism as an economic activity and as an economic area with high social and cultural consequences in the organizational structures of economic entities (Silva et al., 2017). Tourism has a major impact on employment and production and, as a result, can become an essential tool for economic recovery after a recession. In addition to its economic dimension, tourism has a great social impact (Rontos et al., 2017). However, managers of tourism companies have to control the financial health of the companies. At least intuitively, financial managers and their external financial analytical counterparts recognize that all working capital investments do not have the same life expectancy, nor are they transformed into usable liquidity flows at the same speed. The approach to working capital management in monetary terms illustrates the potential danger of an intuitive approach to liquidity analysis (Richards \& Laughlin, 1980).

The financial analysis involves examining the financial statements of the company to determine how well the company is doing and to acquire an idea of what the company can be expected to perform in the next period. A commonly used technique when evaluating financial statement data is ratio analysis. Profitability ratios show the company's success in achieving net sales or investment returns. These indicators are those that investors usually look at because their main concern is the ability of the company to make a profit. The rate of return on assets (ROA) measures the ability of management to obtain a return on total invested capital using the company's assets. Basically, liquidity is used to measure a company's ability to pay its bills on time. In 
this sense, liquidity measures the ability of a company to meet short-term liquid assets liabilities. The Quick-test (or L2, acid-test) measures a company's ability to meet its shortterm liabilities using those short-term assets that are considered the most liquid. The term 'liquid' refers to assets that can be quickly converted into cash without additional losses. Managers should also become familiar with the activity ratios as they reflect the intensity with which the company uses its assets to generate sales. Neither current liquidity nor Quick-test measures the movement of current assets. Therefore, short-term creditors should use additional tests when considering the liquidity of two significant working capital items, receivables, and inventories. Activity ratios - also known as asset recovery ratios, asset management ratios, or just recovery ratios - measure the effectiveness of a company's asset management. Company assets should be deployed in such a way as to generate profits and returns for the shareholders whose money was used to acquire assets. If a company is not successful in managing its assets, costs tend to overcome profits and the company's performance becomes disrupted. On the other hand, when assets are well managed, the company requires less capital, costs are generally better controlled, and results are not only favorable but tend to improve even more over time. Activity ratios provide an overview of management efficiency as well as asset quality and the reliability of the values assigned to them. Together, these measures form a cash conversion cycle (CCC), which is the time from the outflow of cash until it is recovered (Sherman, 2015).

From a theoretical point of view, in general, if managers want to maximize the profitability of a company, they need to have enough liquidity to invest. The theoretically proposed range for L2 is therefore from 1.00 to 1.50 , which means that short-term liabilities are covered in $100-150 \%$. Whether they are investing in fixed assets (tangible or intangible), this should mean potentially higher incomes and the resulting profit of the company. Richards and Laughlin (1980) argue that assessing the correlation between cash inflows and outflows, which underlies a more complete approach to liquidity analysis, requires an additional flow indicator of current liabilities. According to them, the CCC expresses the net time interval between the actual cash outflows for the purchase of the company's production resources and the final cash yield from the sale of products, which sets the time required to convert cash payments back to cash from the regular operation of the company. However, if managers had sufficient liquidity, a decline in investment would mean an increase in fixed assets and an increase in profitability. Such an increase in profits also increases the potential conflict between management and business owners who want a return on their investment, which also reduces the liquidity of the companies. For example, Dalci and Ozyapici (2018) show that increasing the CCC length for hospitals with high leverage reduces their profitability. Conversely, increasing the length of the cash transfer cycle for those with low leverage effects increases profitability. The results of their work suggest that, as leverage affects the relationship between the cash conversion cycle and profitability, leverage is an important indicator that should be taken into account by managers and policymakers in managing the working capital of hospitals. On the other hand, revenues being reinvested by the owners back into the business, especially in a period of the global financial crisis, represent a significant encouragement to the company to survive and generate higher returns in the future. Creating or not generating retained earnings could play a key role, especially in times of crisis.

Unlike previous studies, Baños-Caballero et al. (2014) found strong support for an inverted U-shaped relationship between working capital investment and business performance, which means an optimal level of working capital investment, which balances costs and revenues and maximizes business value. In their view, the positive and negative effects of working capital indicate that working capital decisions involve some degree of compromise. Therefore, they expect companies to have an optimal level of working capital that balances these costs and revenues, maximizing the rate of profit. In particular, they expect the performance of companies to increase as working capital increases until the optimum level of working capital is reached. On the contrary, they expect that, in addition to this optimum, the relationship between working capital and performance will be negative. Their results indicate that managers should avoid negative impacts on business performance due to loss of sales and 
loss of early payment discounts or additional financial costs. Ben-Nasr (2016) also examines whether state and foreign ownership influence the shape of the net working capital curve. According to the main results, shareholders value less (more) the net working capital in government-controlled companies (under foreign control) with a low level of the net working capital compared to foreign-controlled companies (without foreign control). Last but not least, the findings of Mun and Jang (2015) show that companies are finding a strong inverse relationship between working capital and U-profitability, which also suggests that there is an optimal level of working capital in the case of restaurants.

Given that small and medium-sized hotels are particularly important in the economies of the European Union, and in the absence of internal funding, their survival may be threatened by excessive use of short-term debt and limited access to long-term debt (Nunes \& Serrasqueiro, 2017). This study has shown that hotel SMEs adjust short-term debt to target debt ratio and adjust this debt according to the financial deficit, and older ones with a higher level of cash flow resort less to short-term debt as well. On the contrary, they reject that larger hotels SMEs with higher reinsurance rates, those with higher growth or higher risk levels, or larger non-debt tax shields, are more likely to resort to short-term debt. They suggested that the owners/managers of hotel SMEs should try to avoid excessive use of short-term debt in high-risk situations. However, high risk, characterized by high volatility in operating results combined with the need to repay debt and its charges over a very short period of time, could jeopardize the efficient management of financial resources and contribute to increasing the likelihood of bankruptcy in SMEs due to excessive use of short-term debt.

Lee and Dalbor (2013) measured EBIT on total returns and carried out the same analysis as sensitivity analysis, as the restaurant industry widely implements franchising strategies and total return may be a better variable in this case than total assets. However, very similar results appear when using both different approaches to measuring performance. For EBIT, short-term debt generally has a negative impact during the recession-free period, while this negative effect disappears during the recession. The findings clearly indicate that in times of recession the use of short-term debt plays a more positive role in improving the performance of firms in terms of accounting measures. According to the findings, long-term debt adversely affects the company's value in a non-recession period, while it does not affect EBIT in either a nonrecession or recession period. Based on these findings, the company may choose to finance through long-term debt in a recession-free period, when the company's primary goal is to maintain its year-on-year profitability. On the other hand, if the main goal of the company is to maintain its value, the company may decide to increase its short-term financing as much as possible and replace long-term debt in a period without the crisis. In addition, if a restaurant firm focuses more on its performance value than on short-term operating profitability, the use of short-term debt is perhaps a better alternative than long-term debt.

Baños-Caballero et al. (2014) then examine whether the optimal level of working capital is sensitive to alternative measures of financial constraints. To test the effect of financial constraints on the optimal level of working capital, they estimate the optimal working capital investment for different subsamples, divided based on the probability that companies have limited access to external financing. According to them, there are several measures in previous studies that separate businesses suffering from financial constraints from those that do not. However, there is still a question to discuss which measures are the best. Therefore, in their research, they divide companies by the following criteria in terms of the existence of financial constraints, such as (i) dividends, (ii) cash flows, (iii) size, (iv) external financing costs, (v) Whited-Wu index, (vi) interest coverage and (vii) Z-scores. Their results show that the optimum is lower for companies that are more likely to be financially constrained. Ben-Nasr (2016) found that the negative (positive) relationship between state (foreign) ownership and the net working capital is stronger in companies that are less financially constrained (from countries with strong government institutions), especially at the low level of the net working capital.

\section{Data and Methodology}

Annual data for medium-sized hotels and travel agencies from the Czech Republic are obtained from two international statistical databases. 


\section{Business Administration and Management}

First, Amadeus financial data are obtained for the time period from 2006 to 2015. Second, Orbis financial data are obtained for the period from 2009 to 2017. Because of the comparison of these two periods concluding remarks are made. In particular, it is obtained from the number of total assets, current assets, inventories, shareholders' funds which included the capital, current liabilities, all from tourism companies' balance sheets, and earnings before interest and taxes from their profit and loss statements.

According to Sherman (2015), the next four variables are examined by using these data above. The profitability of tourism companies is explored as the return on assets according to Formula 1:

$$
R O A_{i t}=\frac{E B I T_{i t}}{T A_{i t}} * 100,
$$

where $E B I T_{i t}$ are earnings before interest and taxes and $T A_{i t}$ means total assets, both $i$ companies at time $t$.

Liquidity of selected firms is measured through the acid- or Quick-test, which is described by the following Formula 2:

$$
L 2_{i t}=\frac{C A_{i t}-I N_{i t}}{C L_{i t}}
$$

where $C A_{i t}$ means current assets, $I N_{i t}$ stands for inventories, and $C L_{i t}$ is current liabilities of medium-sized hotels or medium-sized travel agencies.

A share of the net working capital on total assets is calculated by Formula 3 to explore the risk, how the earnings are reached:

$$
W C R_{i t}=\frac{C A_{i t}-C L_{i t}}{T A_{i t}} * 100 .
$$

A retained earnings ratio as a share of total assets is calculated to explore reinvestments back to tourism companies by Formula 4:

$$
R E R_{i t}=\frac{S F_{i t}-C P_{i t}}{T A_{i t}} * 100,
$$

where $S F_{i t}$ stands for shareholders funds, $C P_{i t}$ is the capital and when we make this difference, then just retained earnings remained.

Tab. 1 shows the medians for selected variables of medium-sized enterprises in the Czech Republic. In case of return on assets $R O A_{i t}$, we see that the median is practically zero (even if the agencies reach higher value). Thus, we can say that practically more than half of companies face poor profitability. The $L 2_{i t}$ liquidity median, on the other hand, suggests that more than half of tourism businesses have no liquidity problems. However, we see a fundamental difference between hotels and agencies in terms of the share of working capital $W C R_{i t}$ and the share of reinvested earnings $R E R_{i t}$. While the $W C R_{i t}$ median is positive for the agencies and thus fulfills the assumption of lower risk in business, the $W C R_{i t}$ median is zero for hotels. It implies that mediumsized hotels have worse stability, which is also confirmed by the negative zero value in

\section{Tab. 1: Medians and number of observations among variables}

\begin{tabular}{l|c|c|c|c} 
& $R O A_{i t}$ & $L 2_{i t}$ & $W C R_{i t}$ & $R E R_{i t}$ \\
\hline \multirow{3}{*}{ Hotels Amadeus } & 0.0044 & 0.7546 & -0.0492 & -0.0030 \\
\cline { 2 - 5 } & 3,631 & 3,563 & 3,631 & 3,631 \\
\hline \multirow{2}{*}{ Hotels Orbis } & 0.0045 & 0.7674 & -0.0393 & -0.0332 \\
\cline { 2 - 5 } & 3,091 & 3,057 & 3,091 & 3,091 \\
\hline \multirow{2}{*}{ Agencies Amadeus } & 0.0569 & 1.1810 & 0.1333 & 0.1044 \\
\hline \multirow{2}{*}{ Agencies Orbis } & 1,454 & 1,435 & 1,454 & 1,454 \\
\cline { 2 - 5 } & 1,227 & 1.1935 & 0.1416 & 0.1945 \\
\hline
\end{tabular}

Source: own calculations in STATA 16 
the case of the median for $R E R_{i t}$. Contrary to that, agencies literally donate their owners with their redistributed profits. In the case of tourism businesses, the sad truth is that many owners operate a medium-sized hotel or travel agency only as a secondary activity, a safeguard for their core business.

As the main estimation method will be used the General Method of Moments (GMM, described later by Formula 5). Nonetheless, in terms of methodology, the question arises as to why the GMM. Of course, short time series can become the argument when it is impossible to use ordinary least squares (OLS), the linear regression method. The first thing to think about is the question of endogeneity. If there is a variable on the right side of the equation, which may also be a dependent variable from the perspective of endogeneity, then we are talking about the problem of endogeneity where a single equation does not explain the situation. Dependent variables can be both variables, so the solution can be found by combining both of these opposite equations. In the case of a simple equation and the existence of only two variables, we can solve this problem by using the 2SLS method (Two-Stage Least Squares), and by inserting a strongly correlated instrument into the equation, which is not correlated with the dependent variable on the left side of the equation. Consequently, there are two equations, by the combination of which we get a single point representing the solution A of a given situation in Fig. 1.

The problem arises when other problematic variables would be added due to their endogeneity. 3SLS (Three-stage) represents a combination of two 2SLS approaches, however, in order to achieve a robust solution, the use of the Generalized Least Squares (GLS) method and the determination of the weights of the individual solutions are appropriate. The endogeneity problem could be solved using the instrumental variables among the regressors that are correlated with exogenous variables but not with the endogenous. All the above approaches except the GMM assume the absence of heteroscedasticity of the model residual component. However, the problem of heteroscedasticity is a problem to be assumed in terms of panel data and a short time series, and only the use of GMM seems to be effective, where the final solution is achieved by allocating weights to the individual solutions within the panel when the area between points A, B, C is narrowed to a single point approaching the solution of the given equation in Fig. 1 .

Therefore, the two-step GMM model with panel data for medium-sized hotels and travel agencies is described in the following way,

\section{Fig. 1: Why to use the GMM regression?}

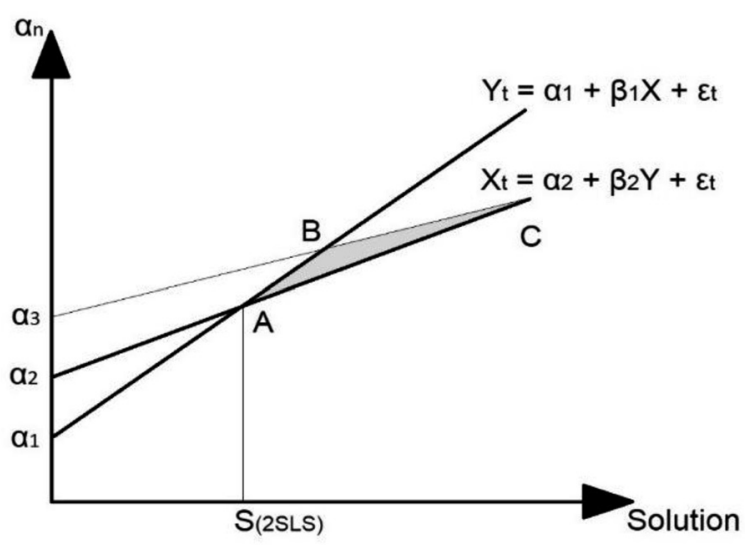

Source: own illustration based on materials from Timberlake STATA course with Giovanni Cerulli (at Cass Business School of City, University of London, 2019) 
by Formula 5 (more technically in Heryán \& Tzeremes, 2017):

$$
\begin{aligned}
& R O A_{i t}=R O A_{i(t-1)}+L 2_{i t}+W C R_{i t}+ \\
& +R E R_{i t}+\alpha+\delta+\varepsilon_{i t}
\end{aligned}
$$

$R O A_{i(t-l)}$ among regressors, symbols $\alpha$ and $\varepsilon_{i t}$ are the constant and residuals and $\delta$ captures a time effect common to all medium-sized hotels or travel agencies.

\section{Discussion on Results}

Technically, each result is checked in two ways. First, in terms of orthogonality by the SarganHansen test (Sargan, 1958; Hansen, 1982). This test simply confirms the null hypothesis above 0.05 saying that too many variables are not present in the equation and the GMM model is not oversized (Heryán \& Tzeremes, 2017). Fig. 2 shows that it is advisable to have values higher than 0.05 , or 0.10 , to which extent it is considered a gray zone. From this value on, however, the solution is already acceptable. Fig. 2 further shows that it is also unacceptable if the test result is close to 1.00. In terms of the elasticity of the orthogonality function, although its elasticity changes, it cannot be said that the result 0.90 is more optimal than the result 0.20 . The lower values of the Sargan-Hansen test for
Orbis data models are caused by shorter time series.

Second, the Arellano-Bond test (Arellano \& Bond, 1991) serves to accept the null hypothesis of no cross-correlation between model residues for individual companies within the panel. The Durbin-Watson test is definitely an inadequate test for the residual component of panel regression models because it is unable to detect these cross-correlations. According to Heryán and Tzeremes (2017), the residual (1) can be the only one to be correlated, while the other residuals (2) and residuals (3) are no longer correlated. In all cases, this condition was fulfilled.

The first thing is seen in Tab. 2, which shows the estimates of GMM models with data in the panel for hotels $(\mathrm{H})$ and travel agencies $(A)$, coming from two databases, is that the situation could not be modeled for all midsized businesses. Of the total number of data collected, only $2,438(70 \%)$ hotels could be modeled due to sufficient internal financial data from 2006 to 2015 from the Amadeus database and only $1,946(60 \%)$ hotels from the Orbis database from 2009 to 2017. In the case of travel agencies, it was only $1,003(70 \%)$ for the Amadeus database and $762(60 \%)$ for the Orbis database.

\section{Fig. 2: Sargan-Hansen test criterion for orthogonality}

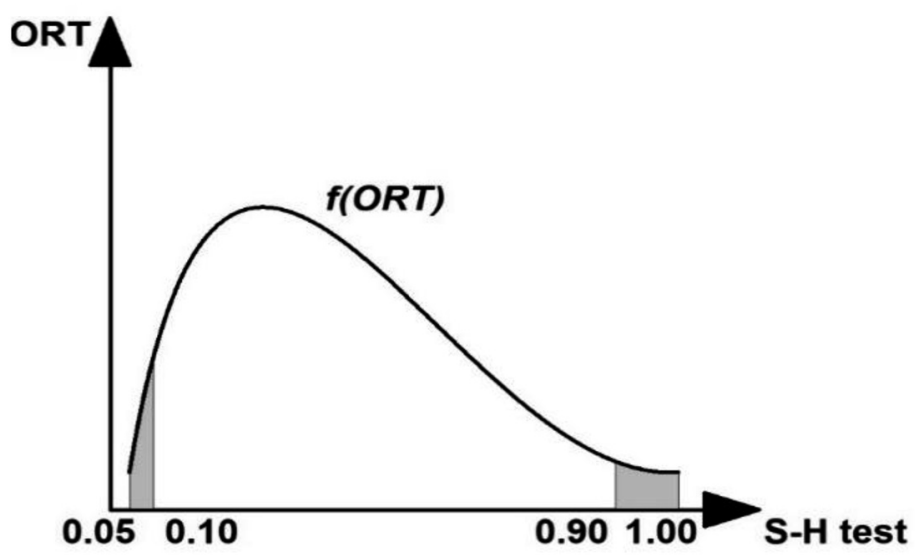

Source: own illustration based on materials from Timberlake STATA course with Giovanni Cerulli (at Cass Business School of City, University of London, 2019) 
Tab. 2: Estimation results of GMM models with panel data (ROA as dependent variable)

\begin{tabular}{l|c|c|c|c|c|c|c|c|c|c}
$R O A_{i t}$ & $R O A_{i(t-1)}$ & $L 2_{i t}$ & $W C R_{i t}$ & $R E R_{i t}$ & Cons. & $\mathrm{N}$ & $\begin{array}{c}S-H \\
\text { test }\end{array}$ & $\begin{array}{c}A-B \\
(1)\end{array}$ & $\begin{array}{c}A-B \\
(2)\end{array}$ & $\begin{array}{c}A-B \\
(3)\end{array}$ \\
\hline $\begin{array}{l}\text { Hotels } \\
\text { Amadeus }\end{array}$ & $\mathbf{0 . 1 9}$ & $\mathbf{0 . 0 0}$ & $\mathbf{0 . 1 1}$ & $\mathbf{- 0 . 0 6}$ & $0.00 \times$ & 2438 & 0.18 & 0.00 & 0.93 & 0.25 \\
\hline $\begin{array}{l}\text { Hotels } \\
\text { Orbis }\end{array}$ & $\mathbf{0 . 0 0}$ & $\mathbf{0 . 0 0}$ & $\mathbf{0 . 0 7}$ & $\mathbf{- 0 . 0 1}$ & $-0.01 \times$ & 1946 & 0.10 & 0.02 & 0.43 & 0.55 \\
\hline $\begin{array}{l}\text { Agencies } \\
\text { Amadeus }\end{array}$ & $\mathbf{0 . 1 6}$ & $\mathbf{- 0 . 0 1}$ & $\mathbf{0 . 2 8}$ & $\mathbf{- 0 . 3 9}$ & 0.08 & 1003 & 0.65 & 0.00 & 0.81 & 0.71 \\
\hline $\begin{array}{l}\text { Agencies } \\
\text { Orbis }\end{array}$ & $\mathbf{- 0 . 0 8}$ & $\mathbf{0 . 0 0}$ & $\mathbf{- 0 . 0 6}$ & $\mathbf{- 0 . 0 0 \times}$ & 0.09 & 762 & 0.16 & 0.01 & 0.40 & 0.37 \\
\hline
\end{tabular}

Source: own calculations in STATA 16

Note: All coefficients are significant at $1 \%$ level, except for those non-significant, marked with $\mathrm{x}$. S-H test means Sargan-Hansen test for orthogonality and A-B means Arellano-Bond test for serial correlation with 1, 2 and 3 lags. According to the use of two-step GMM model as well as differencing time series, the estimation period is shorter, the pre-crisis from 2006 to 2013 within Amadeus and the post-crisis from 2009 to 2015 within Orbis database.

Regarding hotels based on modeling with Amadeus data, it is clear that the profitability from the previous year $R O A_{i(\mathrm{t}-1)}$ has a positive impact on their profitability in the following year. This means that despite the onset of the global financial crisis, hotels managed to achieve some profit. While $L 2_{i t}$ liquidity does not play a crucial role in terms of profitability, we can see that in case of a positive impact of the net working capital ratio on total assets $W C R_{i t}$, this profitability is achieved in a safer way when hotels are able to create an emergency safety cushion. Due to the inclusion of the crisis period in the examined time period, a fundamental difference from the classic situation is obviously contrary to classic status, when the increase in working capital affects profitability in the negative direction. The negative impact is logical in terms of holding sales in receivables, which clearly leads to lower profits. However, profits need to be made in times of crisis, even if working capital is to be increased. From the point of view of reinvestments back to the business, it is clear that the $R E R_{i t}$ coefficient does not become positive. This may be related to lower hotels' profitability, but also to the fact that all profits are distributed to owners. Three years later, based on modeling with data from the Orbis database, hotels were no longer doing so well that their previous profitability would mean current profits, nor would they generate profits due to the net working capital. In the second monitored period, we can already see the impacts of the global financial crisis, which fully reflected the further development of medium-sized hotels in the Czech Republic. In the case of travel agencies and time series from the Amadeus database, it can be seen that the profitability of the previous year $R O A_{i(\mathrm{t}-1)}$ positively affects the current profitability again. The liquidity $L 2_{i t}$ does not play a role due to a zero, statistically significant coefficient, however, the ability to generate the net working capital, a positive $W C R_{i t}$ is again apparent and companies are providing economic activities in a safer way. Compared to hotels, however, the negative impact of the share of reinvested profit, and a negative $R E R_{i t}$ is seen, which means that the owners of travel agencies in the Czech Republic distribute not only current but also previous profits. When comparing the modeling of medium-sized agencies with data from the Orbis database, we also see a decline in the stability of their business results, where past profitability no longer affects current profits, while failing to meet the assumption of the net working capital creation. The only statistically insignificant coefficient is the $R E R_{i t}$ value, where we are unable to say whether the volume of distributed profits has actually decreased.

In terms of comparing two time periods that differ by three years as for the beginning and the end, even if they overlap, we cannot see the change in $L 2_{i t}$. The liquidity $L 2_{i t}$ has no impact on $R O A_{i t}$ as it comes to medium-sized tourist facilities. For hotels and agencies, last year's $R O A_{i(\mathrm{t}-1)}$ value has a much greater positive impact on profitability growth within the earlier 
period than within the post-crisis one. The increase in $W C R_{i t}$ has also a positive impact on profitability only in years including the pre-crisis period. In the case of travel agencies, it can be stated that over time they not only reduce profits but also achieve them under riskier conditions. Hotels, however, are doing no better, as it was already apparent from the point of view of their median values that the crisis hit them to a much greater extent. That is why hotel owners were not able to distribute as much profit as agencies, which results from $R E R_{i t}$ coefficients in years including the pre-crisis period. Declining numbers of medium-sized businesses, both hotels and travel agencies, are also alarming. This is likely to mean an increasing number of bankrupted companies.

\section{Conclusions}

The aim of this paper was to estimate the relationship between profitability and both, working capital management and reinvestments of companies' owners of medium-sized hotels and travel agencies in the period affected by the financial crisis. The times of the global financial crisis, including their effects, can hardly be measured. However, thanks to the comparison of two time periods, one of which included the pre-crisis period, while the other one post-crisis one, two aspects were identified. First, the positive impact of the net working capital management on profitability caused by the effects of the financial crisis is unsustainable and is disappearing for hotels and travel agencies. In particular, travel agencies, which by their nature are capable of generating a greater number of receivables and payables than in the case of hotels, were no longer profitable in the second reporting period, assuming the net working capital formation. However, the question is whether its optimum level has already been reached and whether it was no longer necessary to create it or whether it was no longer possible to create it. Secondly, the owners of medium-sized hotels and travel agencies did not help these companies during the global financial crisis; on the contrary, they shared the profits even of previous years. This phenomenon may be mainly caused by the fact that the owners of similar, medium-sized tourism companies, are mainly persons engaged in other core business activities. This may also result in a decreasing number of market players during the reported period.
However, the key finding remains that the managers of medium-sized tourism companies were able to hold a larger amount of cash tied through the working capital. At present, the managers will be subject to greater pressure to generate profits while reducing working capital. In practice, this means a more aggressive payment policy, i.e. reducing the maturity term of receivables and extending the maturity of liabilities. This paper points out the importance of working capital management, where it is clear that this issue needs to be dealt with much deeper. Therefore, in future research, attention will be paid to this direction. However, other market impacts such as the development of the exchange rate or, for example, the number of nights spent in accommodation facilities in selected destinations will be taken into account as well.

\section{Acknowledgment}

This paper was financially supported by SGS/7/2018 'Analysis of the influence of selected aspects on the financial structure among enterprises in the conditions of Central and Eastern European countries'.

\section{References}

Arellano, M., \& Bond, S. R. (1991). Some Tests of Specification for Panel Data: Monte Carlo Evidence and an Application to Employment Equations. Review of Economic Studies, 58(2), 277-297. https://doi. org/10.2307/2297968

Baños-Caballero, S., García-Teruel, P. J., \& Martínez-Solano, P. (2014). Working capital management, corporate performance, and financial constraints. Journal of Business Research, 67(3), 332-338. https://dx.doi. org/10.1016/j.jbusres.2013.01.016

Ben-Nasr, H. (2016). State and foreign ownership and the value of working capital management. Journal of Corporate Finance, 41, 217-240. https://dx.doi.org/10.1016/j. jcorpfin.2016.09.002

Dalci, I., \& Ozyapici, H. (2018). Working capital management policy in health care: The effect of leverage. Health Policy, 122(11), 1266-1272. https://dx.doi.org/10.1016/j. healthpol.2018.09.012

Hansen, L. P. (1982). Large sample properties of generalized method of moments estimators. Econometrica, 50(4), 1029-1054.

Heryán, T., (2017). Were the Czech Hotels Able to Confront Current Appreciation 
of the Czech Currency Before the End of the Exchange Rate Commitment? Acta Universitatis Agriculturae et Silviculturae Mendelianae Brunensis, 65(6), 1925-1933. https://doi.org/10.11118/actaun201765061925

Heryán, T. (2018). Microeconomics of tourism among selected CEE countries: What influences profitability in a case of those profitable firms? (Working Papers, 62). Karviná: Silesian University, School of Business Administration.

Heryán, T., \& Tzeremes, P. G. (2017). The bank lending channel of monetary policy in EU countries during the global financial crisis. Economic Modelling, 67, 10-22. https://dx.doi. org/10.1016/j.econmod.2016.07.017

Lee, S., \& Dalbor, M. C. (2013). ShortTerm Debt and Firm Performance in the US Restaurant Industry: The Moderating Role of Economic Conditions. Tourism Economics, 19(3), 565-581. https://dx.doi.org/10.5367/ te. 2013.0219

Miller, M. H., \& Modigliani F. (1961). Dividend Policy, Growth, and the Valuation of Shares. The Journal of Business, 34(4), 411-433. https://dx.doi.org/10.1086/294442

Mun, S. G., \& Jang, S. S. (2015). Working capital, cash holding, and profitability of restaurant firms. International Journal of Hospitality Management, 48, 1-11. https://dx.doi.org/10.1016/j.ijhm.2015.04.003

Nunes, P. M., \& Serrasqueiro, Z. (2017). Short-term debtand long-term debt determinants in small and medium-sized hospitality firms. Tourism Economics, 23(3), 543-560. https://dx.doi.org/10.5367/te.2015.0529

Richards, V. D., \& Laughlin, E. J. (1980). A Cash Conversion Cycle Approach to Liquidity Analysis. Financial Management, 9(1), 32-38.

Rontos, K., Salvati, L., Syrmali, M. E., Vavouras, I., \& Karagkouni, E. (2017). The geography of tourism in Europe: exploring countries and regions of higher or lower development of tourism in the period of crisis. In Rontos, K., Filipe J. A., \& Tsartas P. (5th Ed.), Modeling and New Trends in Tourism: A Contribution to Social and Economic Development (pp. 21-42). Hauppauge, NY: Nova Science Publishers.

Sagan, J. (1955). Toward a Theory of Working Capital Management. The Journal of Finance, 10(2), 121-129. https://dx.doi.org/10.2307/2976040

Sargan, J. D. (1958). The Estimation of Economic Relationships Using Instrumental Variables. Econometrica, 26, 393-415.

Sherman, E. H. (Eds.). (2015). A Manager's Guide to Financial Analysis: Powerful Tools for Analyzing the Numbers and Making the Best Decisions for Your Business. New York, NY: American Management Association.

Silva, M. A., Ferreira, M. A. M., Filipe, J. A., \& Coelho, M. (2017). The Portuguese tourism market: A model. In Rontos, K., Filipe J. A., \& Tsartas P. (5th Ed.), Modeling and New Trends in Tourism: A Contribution to Social and Economic Development (pp. 12-20). Hauppauge, NY: Nova Science Publishers. 